\title{
Commentary: Contain your excitement: Expanding the role of bilateral sympathectomy in heart disease
}

Peter J. Altshuler, MD, and Pavan Atluri, MD

\footnotetext{
From the Division of Cardiovascular Surgery, Department of Surgery, University of Pennsylvania, Philadelphia, $\mathrm{Pa}$.

Disclosures: Authors have nothing to disclose with regard to commercial support

Received for publication Oct 1, 2019; revisions received Oct 1, 2019; accepted for publication Oct 2, 2019 available ahead of print Oct 15, 2019.

Address for reprints: Pavan Atluri, MD, Division of Cardiovascular Surgery, Department of Surgery, Hospital of the University of Pennsylvania, 3400 Spruce St, 6 Silverstein, Philadelphia, PA 19104 (E-mail: pavan.atluri@ pennmedicine.upenn.edu).

J Thorac Cardiovasc Surg 2020;160:e145-6

$0022-5223 / \$ 36.00$

Copyright (c) 2019 by The American Association for Thoracic Surgery

https://doi.org/10.1016/j.jtcvs.2019.10.011
}

Sympathetic nervous system activation stimulates both myocardial inotropy and chronotropy. In a diseased heart, however, adrenergic stimuli may overwhelm diseased myocardium, resulting in adverse myocardial remodeling. ${ }^{1}$ Traditional therapies to counteract this include ratecontrolling agents, renin-angiotensin-aldosterone system antagonists, and other medications designed to suppress adrenergic effects. These medications, however, do not prevent disease progression. ${ }^{2}$ Studies evaluating sympathetic activity in refractory ventricular arrhythmias, myocardial infarction, and systolic heart failure have demonstrated that sympathetic blockade via lateral sympathectomy (LS) can lessen adverse remodeling and improve outcomes. ${ }^{3-5}$ LS, however, may allow for re-recruitment of sympathetic stimulation via contralateral neuronal hypertrophy. ${ }^{6}$ To prevent this re-recruitment, bilateral sympathectomy (BS) has been proposed as a potential treatment and in models of ischemia and malignant arrhythmias has shown promising long-term results with an acceptable safety profile. ${ }^{7,8}$

In this issue of the Journal, Coutinho e Silva and colleagues ${ }^{9}$ use current understanding of the therapeutic efficacy of BS, intending to expand its utility to a model of dilated cardiomyopathy (DCM). Rats with doxorubicininduced DCM were stratified by no treatment, medical treatment with an angiotensin-converting enzyme inhibitor (ACE-I), and BS via chemical sclerosis of the stellate ganglion on experimental day 15 (a fourth group sham group was used as a negative control). Overall mortality at 10 weeks post-DCM induction was markedly reduced in both treatment groups (10\% for ACE-I and BS vs $42 \%$ for DCM). Both BS and ACE-I demonstrated preserved left ventricular function during dobutamine stimulation compared with rats with DCM, although only the BS group preserved steady-state hemodynamics and preloadrecruitable stroke work. Histologically, both ACE-I and BS decreased left ventricular dilation. Molecular analysis through quantitative analysis of proteins B-cell guidelines.

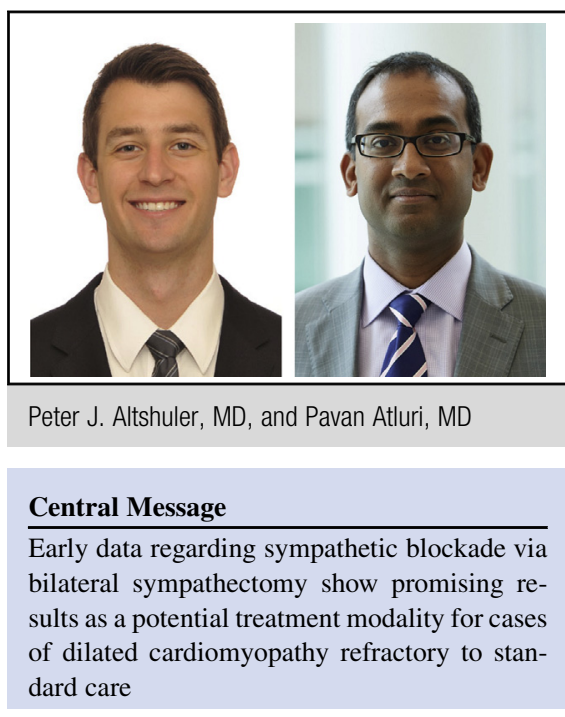

See Article page e135.

lymphoma-2, vascular endothelial growth factor, intercellular adhesion molecule, vascular cell adhesion molecule, and matrix metallopeptidase-9 were suggestive of BS, again providing therapeutic efficacy over ACE-I, although these findings were more nuanced.

Overall, Coutinho e Silva and colleagues provide important steps in a bench-to-bedside evaluation of the use of BS to protect against the adverse effects of sympathetic remodeling in DCM. Although the demonstrated reduction in mortality and preservation of left ventricular geometry and function is promising, the ambitious nature of the study yields results that raise more questions across many domains. At a molecular level, continued investigation of sympathetic inhibition via BS on both acute and chronic stages of DCM will help guide understanding of the underpinnings behind its modulation of ventricular remodeling. Extending toward clinical relevance, comparison of BS against multimodal medical therapy as well as LS in both short and long term may help tailor future treatment

The findings presented by the authors merit commendation for providing a framework for future investigation in a promising treatment modality for DCM. Conservative treatment modalities currently exist and function to improve longevity and quality of life in many patients with $\mathrm{DCM}^{10}$; still, there exists a subset of progressive or refractory cases 
in which more invasive treatment via BS may provide benefit.

\section{References}

1. Konstam MA, Kramer DG, Patel AR, Maron MS, Udelson JE. Left ventricular remodeling in heart failure: current concepts in clinical significance and assessment. JACC Cardiovasc Imaging. 2011;4:98-108.

2. Matsumura Y, Hoshikawa-Nagai E, Kubo T, Yamasaki N, Furuno T, Kitaoka H, et al. Left ventricular reverse remodeling in long-term ( $>12$ years) survivors with idiopathic dilated cardiomyopathy. Am J Cardiol. 2013;111:106-10.

3. Schwartz PJ. Cardiac sympathetic denervation to prevent life-threatening arrhythmias. Nat Rev Cardiol. 2014;11:346-53.

4. Ziegler KA, Ahles A, Wille T, Kerler J, Ramanujam D, Engelhardt S. Local sympathetic denervation attenuates myocardial inflammation and improves cardiac function after myocardial infarction in mice. Cardiovasc Res. 2018:114:291-9.

5. Conceição-Souza GE, Pêgo-Fernandes PM, Cruz FD, Guimarães GV, Bacal F, Vieira ML, et al. Left cardiac sympathetic denervation for treatment of symptomatic systolic heart failure patients: a pilot study. Eur J Heart Fail. 2012;14:1366-73.

6. Fioretto ET, Rahal SC, Borges AS, Mayhew TM, Nyengaard JR, Marcondes JS, et al. Hypertrophy and neuron loss: structural changes in sheep SCG induced by unilateral sympathectomy. Int J Dev Neurosci. 2011;29:475-81.

7. Zanoni FL, Simas R, da Silva RG, Breithaupt-Faloppa AC, Coutinho e Silva RD, Jatene FB, et al. Bilateral sympathectomy improves postinfarction left ventricular remodeling and function. J Thorac Cardiovasc Surg. 2017;153:855-63.

8. Assis FR, Krishnan A, Zhou X, James CA, Murray B, Tichnell C, et al. Cardiac sympathectomy for refractory ventricular tachycardia in arrhythmogenic right ventricular cardiomyopathy. Heart Rhythm. 2019;16:1003-10.

9. Coutinho e Silva RD, Zanoni FL, Simas R, Martins da Silva MHF, Armstrong Junior R, de Jesus Correia C, et al. Effect of bilateral sympathectomy in a rat model of dilated cardiomyopathy induced by doxorubicin. J Thorac Cardiovasc Surg. 2020;160:e135-44.

10. Bozkurt B, Colvin M, Cook J, Cooper LT, Desawal A, Fonarow GC, et al. Current diagnostic and treatment strategies for specific dilated cardiomyopathies: a scientific statement from the American Heart Association. Circulation. 2016;e579-646. 